\title{
Accelerated growth during childhood is associated with increased arterial stiffness in prepubertal children
}

\author{
Catarina Pais $^{\mathrm{a}, 1}$, Liane Correia-Costa ${ }^{\mathrm{a}, \mathrm{b}, \mathrm{c}, *, 1}$, Cláudia Moura ${ }^{\mathrm{c}, \mathrm{d}}$, Cláudia Mota $^{\mathrm{d}}$, Milton Severo a,e, \\ António Guerra ${ }^{\text {d,f }}$, José Carlos Areias ${ }^{\mathrm{c}, \mathrm{d}}$, Franz Schaefer ${ }^{\mathrm{g}}$, Alberto Caldas Afonso ${ }^{\mathrm{a}, \mathrm{b}, \mathrm{c}}$, Henrique Barros ${ }^{\mathrm{a}, \mathrm{e}}$, \\ Ana Cristina Santos ${ }^{\mathrm{a}, \mathrm{e}}$, Ana Azevedo ${ }^{\mathrm{a}, \mathrm{e}}$
}

a EPIUnit-Institute of Public Health, University of Porto, Porto, Portugal

b Division of Pediatric Nephrology, Integrated Pediatric Hospital, Centro Hospitalar São João, Porto, Portugal

c Department of Pediatrics, Faculty of Medicine of University of Porto, Portugal

${ }^{\mathrm{d}}$ Division of Pediatric Cardiology, Integrated Pediatric Hospital, Centro Hospitalar São João, Porto, Portugal

e Department of Clinical Epidemiology, Predictive Medicine and Public Health, Faculty of Medicine of University of Porto, Portugal

${ }^{\mathrm{f}}$ Division of Pediatric Nutrition, Integrated Pediatric Hospital, Centro Hospitalar São João, Porto, Portugal

${ }^{g}$ Division of Pediatric Nephrology, Center for Pediatrics and Adolescent Medicine, University of Heidelberg, Heidelberg, Germany

\section{A R T I C L E I N F O}

\section{Article history:}

Received 19 November 2015

Accepted 22 November 2015

Available online 23 November 2015

Excessive weight affects the vasculature both indirectly, through several associated cardiovascular risk factors, and directly, through the inflammatory molecules released by the adipose tissue [1]. Since cardiovascular events are rare in children, the consequences of adiposity are generally assessed by evaluating only intermediate vascular phenotypes. Hypertension and increased arterial stiffness may arise in the very early stages of life and there is evidence that these phenotypes can be influenced by birthweight and patterns of weight gain during infancy and childhood [2]. However, the majority of the existing studies rely on a limited number of measurements, the samples are usually small, and the time between the measurement of exposures and outcomes is long. Also, most evaluate the consequences in adolescence or later in life, whereas evidence on the effect of growth on these outcomes in childhood is scarce and the results are inconsistent. The aim of this study was to assess the influence of trajectories of weight gain from birth to 6 years of age on arterial stiffness in 8-9-year-old healthy children.

We studied a sample of children aged 8-9 years followed since birth in a previously established cohort study (Generation XXI, Porto, Portugal). From the original cohort $(n=8647)$, we screened children consecutively according to the date of their 7-year-old evaluation, and

\footnotetext{
* Corresponding author at: Instituto de Saúde Pública da Universidade do Porto (ISPUP), Rua das Taipas, 135, 4050-600 Porto, Portugal. E-mail address: liane@med.up.pt (L. Correia-Costa).

${ }^{1}$ Both authors contributed equally to this paper.
}

excluded those with chronic diseases or chronic usage of medication affecting blood pressure or glucose or lipid metabolism. Between August 2013 and August 2014, 324 children were enrolled and 281 included in the final analysis, after excluding 43 participants for whom it was not possible to estimate a growth trajectory. This sample provides a statistical power of about $80 \%$ to detect a mean difference in PWV of $0.4 \mathrm{~m} / \mathrm{s}$ [3], assuming the study sample's standard deviation of $0.6 \mathrm{~m} / \mathrm{s}$ for $\mathrm{PWV}$, and a ratio of 5:1 between the number of children in the reference growth trajectory and the trajectory with fewest children, at a significance level of $5 \%$, in each sex.

Ambulatory blood pressure monitoring for $24 \mathrm{~h}$ (ABPM) was performed with a portable non-invasive oscillometric blood pressure recorder (Spacelabs Healthcare ${ }^{\circledR}$, model 90207). The non-dominant arm was used and cuff size was chosen according to patient's arm circumference. Carotid-femoral PWV analysis was performed by a single trained cardiopneumology technician with a portable device (Micro Medical PulseTrace PWV PT4000®), after at least 15 min of rest. Acquisition of data was considered valid if the digital volume pulse waveform filled $2 / 3$ of the display with little or no noise, and 3 measurements of PWV were performed and averaged for analysis.

The definition of growth trajectories in the whole cohort Generation XXI was based on an extensive body of data of anthropometric measurements abstracted from the children's health books, recorded in routine care, from birth until the age of 6 years. The growth trajectories patterns were defined by the intercept, slope, quadratic and cubic random terms estimated by a mixed model (Normal Mixture Modeling for Model-Based Clustering). The most appropriate models were those that allowed the best homogeneous grouping of the individual patterns of growth. Four different growth trajectories for both sexes together were defined, which, for illustrative purposes, were plotted over the World Health Organization growth charts (Fig. 1). The four trajectories were labeled as "normal weight gain" (trajectory I), "persistent weight gain" (trajectory II), "weight gain during childhood" (trajectory III) and "weight gain during infancy" (trajectory IV). All the trajectories were compared to trajectory I, considered the closest to the standard and desirable pattern of growth in childhood. 

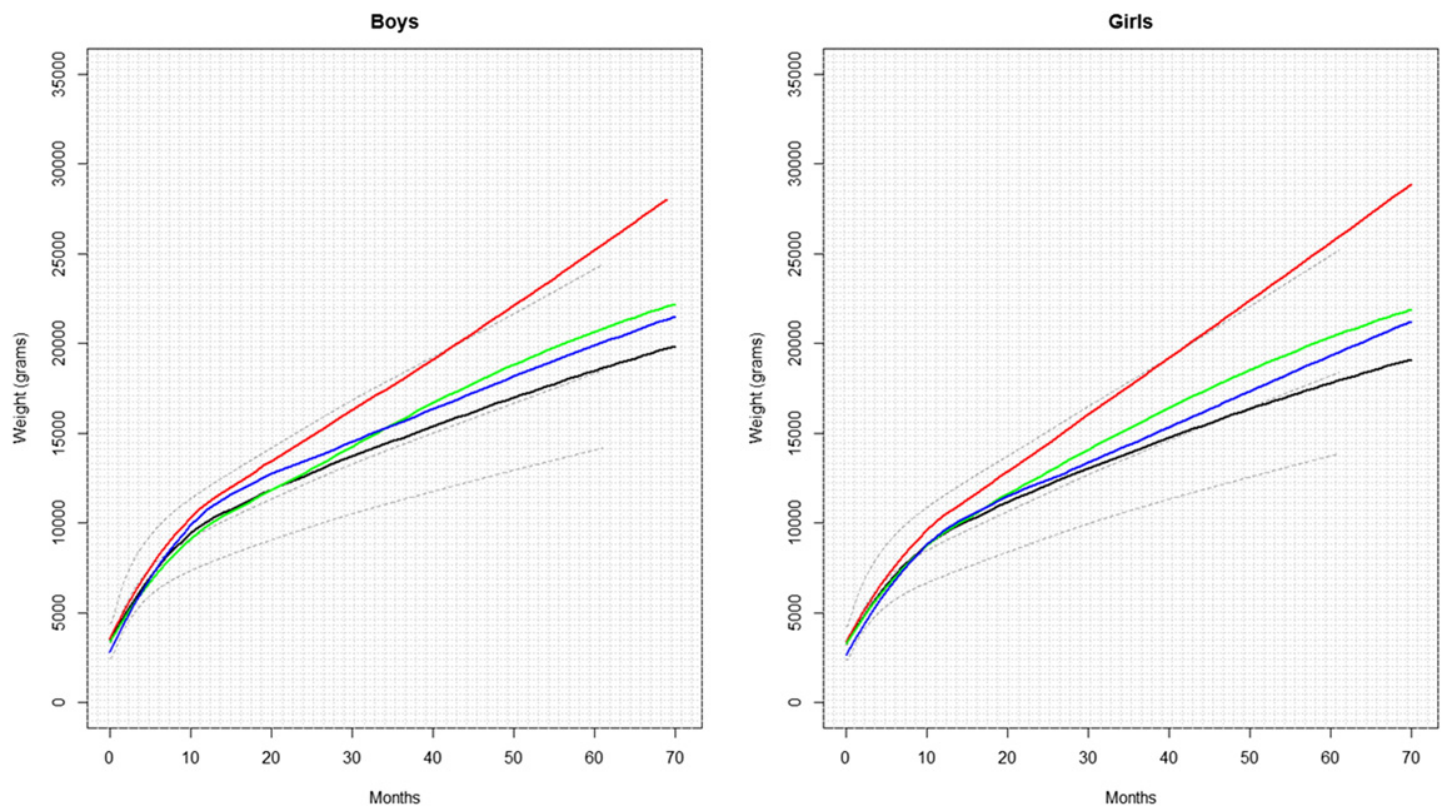

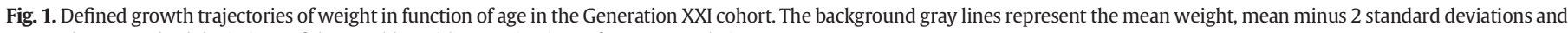
mean plus 2 standard deviations of the World Health Organization reference population.

The Generation XXI study conforms to the ethical principles outlined in the Declaration of Helsinki, the local ethics committee approved the study, and informed consent was obtained.

A total of 281 children (54\% male) with a mean (SD) age of $8.8(0.2)$ years were studied. General characteristics, birth and current anthropometric data by growth trajectories are presented in Table 1. Approximately $53.1 \%$ of the individuals were normal weight, $26.6 \%$ overweight and $20.3 \%$ obese (BMI z-score was categorized according to World Health Organization criteria). There were differences in both current and birth anthropometrics among trajectories $(\mathrm{p}<0.001)$. In both sexes, trajectory I included the greatest percentage of normal weight children and the lowest mean levels of contemporary weight, height and BMI-z score. In turn, trajectory II included the highest anthropometric measurements levels, followed by trajectory III.

Trajectory III was associated with a $0.18 \mathrm{~m} / \mathrm{s}$ (95\% confidence interval: 0.01 to $0.34 \mathrm{~m} / \mathrm{s}$ ) higher PWV than trajectory I ( $\mathrm{p}=0.038$ ), independently of family history of hypertension, children's class of adequacy of birthweight for gestational age, sex and current age, BMI z-score and 24-h systolic blood pressure z-score. No other significant differences were observed between trajectories.

One previous study [4] associated BMI (and not weight) trajectories during infancy and early childhood with later childhood cardiovascular risk factors, namely blood glucose and cholesterol at 5 years of age, in a specific American Indian population. Three studies demonstrated the

Table 1

General characteristics, anthropometric and vascular data, by growth trajectories.

\begin{tabular}{|c|c|c|c|c|c|c|}
\hline & \multirow{2}{*}{$\begin{array}{l}\text { All } \\
\mathrm{n}=281\end{array}$} & \multirow{2}{*}{$\frac{\mathrm{I}}{\mathrm{n}=174}$} & \multirow{2}{*}{$\frac{\mathrm{II}}{\mathrm{n}=27}$} & \multirow{2}{*}{$\begin{array}{l}\mathrm{III} \\
\mathrm{n}=52\end{array}$} & IV & \\
\hline & & & & & $\mathrm{n}=28$ & \\
\hline \multicolumn{7}{|l|}{ Demographic and birth data } \\
\hline Age (months) & $105.2 \pm 2.9$ & $105.1 \pm 3.0$ & $105.4 \pm 2.8$ & $105.4 \pm 2.8$ & $105.5 \pm 3.1$ & 0.742 \\
\hline Gestational age at birth (weeks) & $38.9 \pm 1.4$ & $39.0 \pm 1.1$ & $39.3 \pm 1.2$ & $39.0 \pm 1.0$ & $37.5 \pm 2.4$ & $<0.001$ \\
\hline Birthweight $(\mathrm{g})$ & $3257.42 \pm 445.81$ & $3263 \pm 367$ & $3546 \pm 525$ & $3270 \pm 409$ & $2919 \pm 639$ & $<0.001$ \\
\hline Family history of hypertension ${ }^{a}$ & $55(19.6 \%)$ & $32(18.4 \%)$ & $8(29.6 \%)$ & $10(19.2 \%)$ & $5(17.9 \%)$ & 0.545 \\
\hline \multicolumn{7}{|l|}{ Current anthropometry } \\
\hline Weight $(\mathrm{kg})$ & $33.18 \pm 7.58$ & $30.2 \pm 5.6$ & $42.2 \pm 8.9$ & $36.7 \pm 7.3$ & $36.4 \pm 6.9$ & $<0.001$ \\
\hline Height (cm) & $133.32 \pm 5.98$ & $131.7 \pm 5.5$ & $138.7 \pm 6.1$ & $134.7 \pm 5.2$ & $135.4 \pm 6.2$ & $<0.001$ \\
\hline BMI $\left(\mathrm{kg} / \mathrm{m}^{2}\right)$ & $18.51 \pm 3.15$ & $17.32 \pm 2.43$ & $21.75 \pm 3.33$ & $20.17 \pm 3.24$ & $19.73 \pm 2.84$ & $<0.001$ \\
\hline BMI z-score & $0.99 \pm 1.21$ & $0.54 \pm 1.07$ & $2.16 \pm 0.98$ & $1.58 \pm 1.09$ & $1.50 \pm 1.07$ & $<0.001$ \\
\hline \multicolumn{7}{|l|}{ Classes of BMI ${ }^{\mathrm{b}}$} \\
\hline Normal weight & $147(52.3 \%)$ & $117(67 \%)$ & $3(11 \%)$ & $18(35 \%)$ & $9(32 \%)$ & \\
\hline Overweight & $76(27.0 \%)$ & $44(25 \%)$ & $9(33 \%)$ & $13(25 \%)$ & $10(36 \%)$ & $<0.001$ \\
\hline Obese & $58(20.6 \%)$ & $13(8 \%)$ & $15(56 \%)$ & $21(40 \%)$ & $9(32 \%)$ & \\
\hline \multicolumn{7}{|l|}{ Vascular outcomes } \\
\hline Daytime SBP (mmHg) & $116.59 \pm 7.86$ & $116.4 \pm 7.9$ & $115.9 \pm 6.4$ & $117.4 \pm 8.3$ & $117.1 \pm 8.4$ & 0.813 \\
\hline Daytime DBP (mmHg) & $70.80 \pm 5.22$ & $71.0 \pm 5.1$ & $70.6 \pm 5.5$ & $70.9 \pm 6.0$ & $69.5 \pm 5.0$ & 0.547 \\
\hline Nighttime SBP (mmHg) & $104.14 \pm 7.26$ & $104.2 \pm 7.1$ & $103.7 \pm 5.3$ & $104.3 \pm 8.9$ & $104.1 \pm 7.3$ & 0.988 \\
\hline Nighttime DBP (mmHg) & $58.53 \pm 5.47$ & $59.0 \pm 5.7$ & $57.2 \pm 4.3$ & $58.1 \pm 5.4$ & $57.8 \pm 4.8$ & 0.307 \\
\hline Pulse wave velocity $(\mathrm{m} / \mathrm{s})$ & $5.04 \pm 0.49$ & $4.99 \pm 0.49$ & $5.06 \pm 0.43$ & $5.17 \pm 0.52$ & $5.06 \pm 0.51$ & 0.129 \\
\hline
\end{tabular}

The values presented are mean \pm standard deviation or $\mathrm{n}(\%)$.

BMI, body mass index; SBP, systolic blood pressure; DBP, diastolic blood pressure.

a Children were considered to have family history of hypertension when at least one parent or sibling was reported to be affected.

b The normal weight, overweight and obese group classification is according to the World Health Organization classification for BMI z-score. 
impact of post-natal weight gain on increased arterial stiffness, but only in low birthweight babies. Two of these studies $[5,6]$ only analyzed the first year of life and the other [7] only reported this finding regarding upper limb arteries (no associations with aortic PWV). In 3 other studies [8-10] no association was observed between early weight gain and/or birthweight with arterial stiffness in 10-year-old children, concluding that contemporary levels of adiposity have greater impact on vascular modifications than earlier adiposity [10]. Our study adds the detail about when and at what rate weight increases and shows that more important than contemporary weight is the trajectory during infancy and childhood. Our main finding was that weight gain during childhood, rather than infancy, was detrimental for the vascular profile of prepubertal children. Since arterial stiffness is closely related to organ damage and cardiovascular events in later life, our results support the need for public health strategies targeted to the use of PWV measurements in the clinical practice and the prevention of obesity and related morbidities during the lifetime, starting in childhood.

\section{Sources of support}

The cohort 'Geração XXI' was funded by Programa Operacional de Saúde-Saúde XXI, Quadro Comunitário de Apoio III and Administração Regional de Saúde Norte (Regional Department of Ministry of Health) and Calouste Gulbenkian Foundation. This project was supported by FEDER funds from Programa Operacional Factores de Competitividade-COMPETE (FCOMP-01-0124-FEDER028751) and by national funds from the Portuguese Foundation for Science and Technology, Lisbon, Portugal (PTDC/DTP-PIC/0239/2012). Liane Correia-Costa was supported by the Portuguese Foundation for Science and Technology (grant SFRH/SINTD/95898/2013) and Franz Schaefer was supported by the ERA-EDTA Research Program and the KfH Foundation for Preventive Medicine.

\section{Conflict of interest}

The authors report no relationships that could be construed as a conflict of interest.

\section{References}

[1] A. Singhal, I.S. Farooqi, T.J. Cole, S. O'Rahilly, M. Fewtrell, M. Kattenhorn, et al., Influence of leptin on arterial distensibility: a novel link between obesity and cardiovascular disease? Circulation 106 (15) (2002) 1919-1924.

[2] M.B. von Bonsdorff, T. Törmäkangas, T. Rantanen, M.K. Salonen, C. Osmond, E. Kajantie, et al., Early life body mass trajectories and mortality in older age: findings from the Helsinki Birth Cohort Study, Ann. Med. 47 (1) (2015) 34-39.

[3] D. Pandit, A. Kinare, S. Chiplonkar, A. Khadilkar, V. Khadilkar, Carotid arterial stiffness in overweight and obese Indian children, J. Pediatr. Endocrinol. Metab. 24 (1-2) (2011) 97-102.

[4] S.M. Lindberg, A.K. Adams, R.J. Prince, Early predictors of obesity and cardiovascular risk among American Indian children, Matern. Child Health J. 16 (9) (2012) 1879-1886.

[5] A.M.V. Evelein, F.L.J. Visseren, C.K. van der Ent, D.E. Grobbee, C.S.P.M. Uiterwaal, Excess early postnatal weight gain leads to thicker and stiffer arteries in young children, J. Clin. Endocrinol. Metab. 98 (2) (2013) 794-801.

[6] J. Osório, Paediatrics: early growth and vascular change, Nat. Rev. Endocrinol. 9 (3) (2013) 129.

[7] P. Salvi, M. Revera, L. Joly, G. Reusz, M. Iaia, S. Benkhedda, et al., Role of birth weight and postnatal growth on pulse wave velocity in teenagers, J. Adolesc. Health Off. Public. Soc. Adolesc. Med. 51 (4) (2012) 373-379.

[8] L.D. Howe, K. Tilling, L. Benfield, J. Logue, N. Sattar, A.R. Ness, et al., Changes in ponderal index and body mass index across childhood and their associations with fat mass and cardiovascular risk factors at age 15, PLoS ONE 5 (12) (2010) :e15186.

[9] D.A. Lawlor, L. Benfield, J. Logue, K. Tilling, L.D. Howe, A. Fraser, et al., Association between general and central adiposity in childhood, and change in these, with cardiovascular risk factors in adolescence: prospective cohort study, BMJ 341 (2010) c6224.

[10] M. Charakida, A. Jones, E. Falaschetti, T. Khan, N. Finer, N. Sattar, et al., Childhood obesity and vascular phenotypes: a population study, J. Am. Coll. Cardiol. 60 (25) (2012) 2643-2650. 